\title{
Influence of implant-abutment connection structure on peri-implant bone level in a second molar: A 1-year randomized controlled trial
}

\author{
Jin-Cheol Kim¹, Jungwon Lee², Sungtae Kim³ ${ }^{3}$ Ki-Tae Koo ${ }^{3}$, Hae-Young Kim, In-Sung Luke Yeo ${ }^{1 *}$ \\ 'Department of Prosthodontics, School of Dentistry and Dental Research Institute, Seoul National University, Seoul, Republic of Korea \\ ${ }^{2}$ Department of Periodontology, Seoul National University Dental Hospital, Seoul, Republic of Korea \\ ${ }^{3}$ Department of Periodontology, Seoul National University School of Dentistry, Seoul, Republic of Korea \\ ${ }^{4}$ Department of Health Policy and Management, College of Health Science, Korea University, Seoul, Republic of Korea
}

\begin{abstract}
PURPOSE. This study aimed to evaluate the effect of two different implant-abutment connection structures with identical implant design on peri-implant bone level. MATERIALS AND METHODS. This clinical study was a patient-blind randomized controlled trial following the CONSORT 2010 checklists. This trial was conducted in 24 patients recruited between March 2013 and July 2015. Implants with internal friction connection were compared to those with external hex connection. One implant for each patient was installed, replacing the second molar. Implant-supported crowns were delivered at four months after implant insertion. Standardized periapical radiographs were taken at prosthesis delivery (baseline), and one year after delivery. On the radiographs, distance from implant shoulder to first bone-to-implant contact (DIB) and peri-implant area were measured, which were the primary and secondary outcome, respectively. RESULTS. Eleven external and eleven internal implants were analyzed. Mean changes of DIB from baseline to 1-year postloading were $0.59(0.95) \mathrm{mm}$ for the external and $0.01(0.68) \mathrm{mm}$ for the internal connection. Although no significant differences were found between the two groups, medium effect size was found in DIB between the connections (Cohen's $d=0.67$ ). CONCLUSION. Considering the effect size in DIB, this study suggested the possibility of the internal friction connection structure for more effective preservation of marginal bone. [J Adv Prosthodont 2019;11:147-54]
\end{abstract}

KEYWORDS: Randomized controlled trial; Dental implant-abutment design; Alveolar bone loss

\section{INTRODUCTION}

The stability of hard and soft tissues around dental implants is one of the most decisive factors for long-term implant

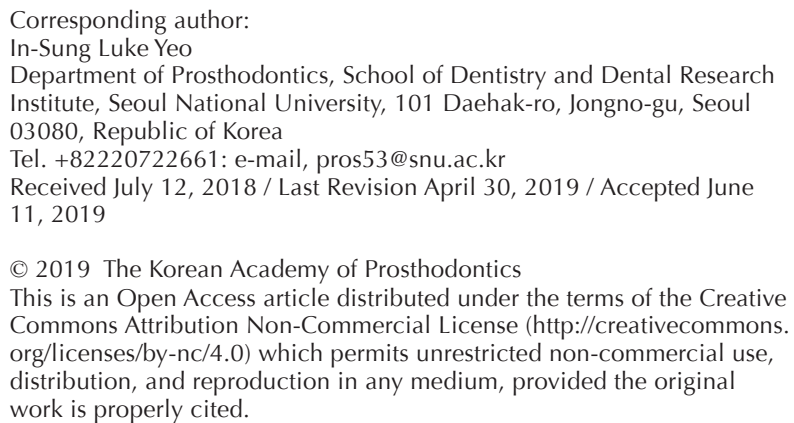

The authors report grants and non-financial support from Shinhung Corporation, Seoul, Korea (Grant No.: NCR13002). This work was also supported by the Mid-Career Researcher Program through a grant from the National Research Foundation of Korea, funded by the Korean government (MSIP) (2016R1A2B4014330). prognosis. ${ }^{1,2}$ Marginal bone loss is a major factor in implant success or failure. ${ }^{3}$ Peri-implant infection plays a role in the marginal bone resorption around a dental implant. ${ }^{4}$

A previous study has suggested several factors that cause the marginal bone loss, including surgical trauma, reformation of biologic width, implant-abutment connection structure, history of periodontitis, and occlusal overloading., ${ }^{5,6}$ Some studies have assessed the effects of implant-abutment connection structure on the marginal bone level change. . $^{-10}$ The implant-abutment connection structure is an important etiologic factor for peri-implant bone remodeling and crestal bone loss, as the highest number of inflammatory cells is infiltrated and the bacteria causing periodontitis are colonized at the microgap of implant-abutment connection. ${ }^{11,12}$

Biomechanical bone responses depending on implantabutment connection structure are also considered to affect marginal bone level at peri-implant sites. Compared to the external hex connection, the internal friction connection structure has been shown to be mechanically more stable and advantageous in force distribution. ${ }^{13,14}$ Some studies 
have reported high stress and marginal bone loss around the external hex connection structure compared with the internal friction. ${ }^{15-17}$ In contrast, other studies have reported that marginal bone loss between two different connection structures is not statistically significant. ${ }^{18,19}$ Inconsistent results might stem from uncontrolled confounding factors of implant design, such as microthread, platform switching, and surface texture.

An occlusal overload could affect peri-implant marginal bone loss. ${ }^{20}$ Because of the biomechanics of the lever system of the mandible and jaw elevator muscles, the occlusal force is greater on the posterior than on the anterior region; hence, relative distribution of occlusal bite force in the posterior region is higher than that in the anterior region. ${ }^{21}$ Therefore, it is necessary to limit implant sites to exclude the difference of occlusal force.

A direct comparison between two different implantabutment connection structures (external hex and internal friction connections) with identical implant design in the posterior region has been rare, especially in the same posterior region. ${ }^{22,23}$ The current study aims to evaluate the effect of implant-abutment connection structure with identical implant design in the second molar region on the periimplant bone level.

\section{MATERIALS AND METHODS}

This single-blind (patient-blind), randomized, parallel, controlled clinical trial was performed according to the principles of the Declaration of Helsinki and was approved by the Institutional Review Board (IRB \#CMP13001), Seoul National University Dental Hospital, Seoul, Korea. The CONSORT 2010 checklists for clinical trials were followed. ${ }^{24}$ Two different connection structures of the implants were compared: external hex connection structure (the control group) and internal friction connection structure (the test group). The study was performed between March 2013 and July 2015 at at Seoul National University Dental Hospital, Korea. The flowchart of this study is presented in Fig. 1.

Patients who met all of the following criteria were eligible for inclusion.

1) Patients aged 20 - 66 years who could undergo surgical treatment

2) Patients who needed to restore a single second molar

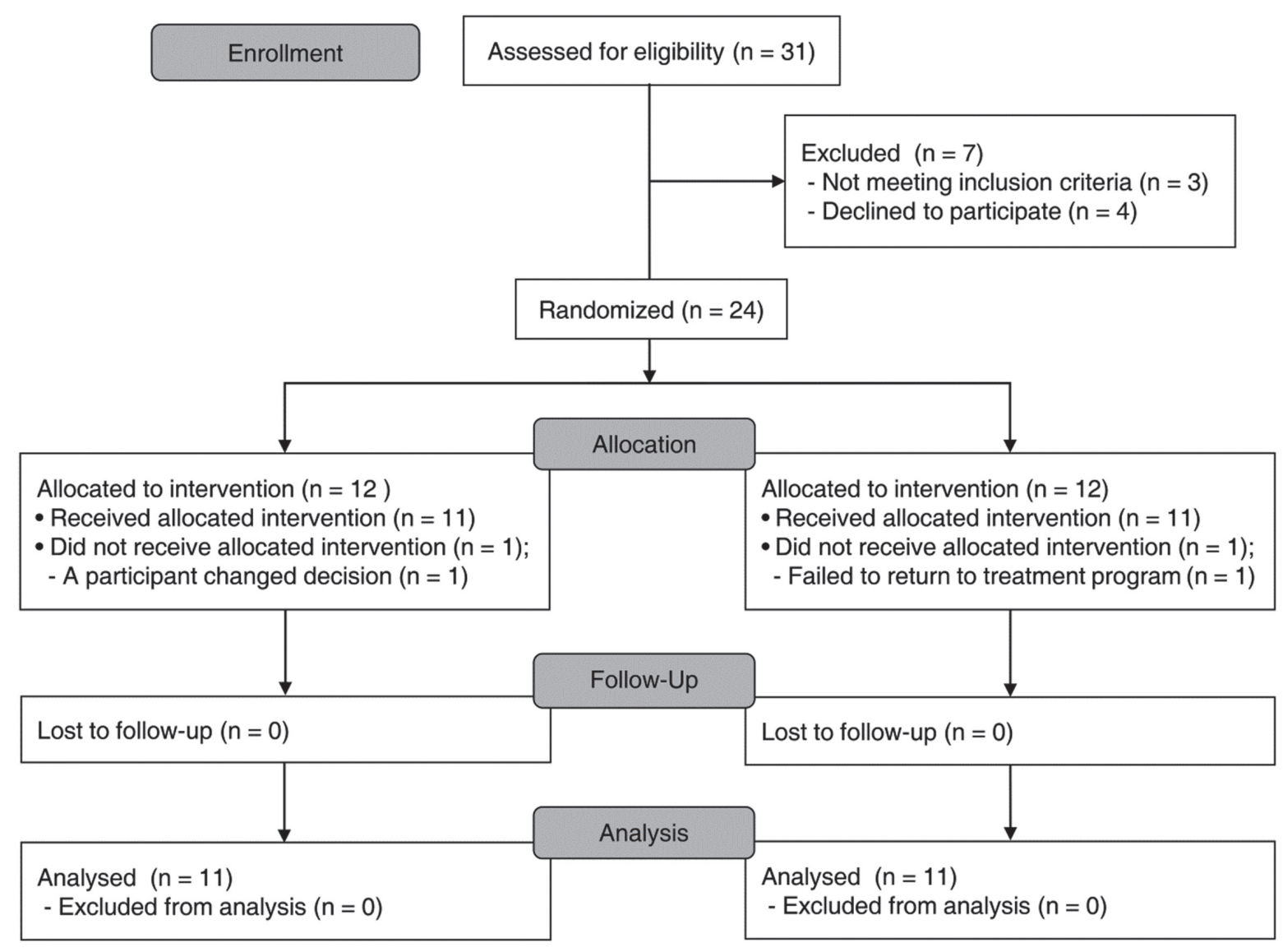

Fig. 1. Flow chart of the study. Twelve subjects were allocated to the control and test groups each. Two patients did not receive allocated interventions. One participant in the control group changed decision and one in the test group did not return to the treatment program. In total, 11 subjects in the control group and 11 in the test group received treatment and were analyzed. 
due to the tooth loss

3) Patients with sufficient healing time of at least 3 months following tooth extraction

4) Patients who agreed to take the test and sign the informed consent form

5) Patients with at least $9 \mathrm{~mm}$ width and $9 \mathrm{~mm}$ height of alveolar bone in cone beam computed tomography analysis.

The exclusion criteria were as follows:

1) Untreated periodontal disease

2) Acute abscess with pain

3) Heavy smokers ( $>10$ cigarettes per day)

4) Parafunctional habit (bruxism, clenching)

5) General contraindications to surgery

6) Participation in other clinical trials that may interfere with the present protocol

Randomization sequence was created using the randomization program on http://www.randomization.com by KTK (Ki-Tae Koo) who didn't perform the treatment. In total, 24 subjects were randomized into six blocks. The allocation was concealed by sealing it in an opaque envelope, and the envelope was opened immediately after the final drilling procedure performed at implant surgery.

Patients were recruited and treated by two different periodontists (JL and SK) and one prosthodontist (ISLY). The treatment was performed using a standardized protocol, and the surgery was conducted by two periodontists on 24 patients (12 in each group). No information was provided to the patients, of which connection structure was received. Detailed explanations were given to all recruited patients and a written informed consent form was obtained before enrolling in the clinical trial.

After local anesthesia using 2\% lidocaine solution with epinephrine 1:100,000 (Huons, Seongnam, Gyeonggi, Korea), a flap was reflected and dental implants (diameter $5.0 \mathrm{~mm}$; length 8.5, 10, or $11.5 \mathrm{~mm}$; Shinhung, Seoul, Korea) were placed at the buccal bone crest level at maxillary or mandibular second molar region according to the manufacturer's recommendation using a non-submerged protocol, and a healing abutment was immediately connected. At implant placement, patients were allocated to either control (external hex connection type; Sola, Shinhung, Seoul, Korea) or test group (internal friction connection type; Luna, Shinhung, Seoul, Korea). The same implant drilling procedure was applied to each group because the implant designs were identical except the implant-abutment connection structures (Fig. 2). No bone augmentation procedure was conducted around the implant placement site. Instructions not to brush the surgical area and to rinse with $0.1 \%$ chlorhexidine (Bukwang Pharmaceutical Co., Seoul, Korea) until suture removal were given to the patients, and the suture was removed 7 - 10 days after surgery. Antibiotics

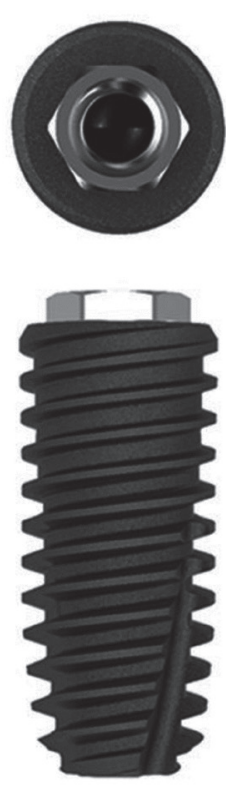

A
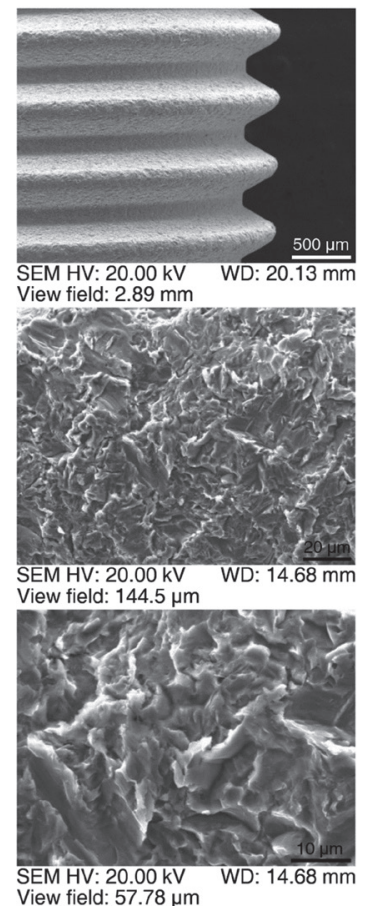
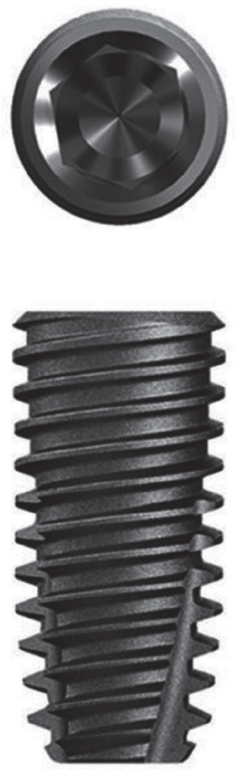

B

Fig. 2. Two implants with different implant-abutment connection structures were used in this study. The control group was an external connection structure (A), and the test group was an internal connection structure (B). Two implants have an identical design such as thread geometry, implant body profile, and surface topography (middle) with the exception of implant-abutment connection structure. The implant thread pitch is $0.8 \mathrm{~mm}$, the thread depth is $0.3-0.45 \mathrm{~mm}$, and the inclination angle of thread flank is $35^{\circ}$. Implant surface was blasted by resorbable blast media, and its arithmetic mean height $\left(R_{a}\right)$ was $1.50-2.00 \mu \mathrm{m}$. 
(Augmentin $625 \mathrm{mg}$ ) and analgesics (acetaminophen 650 $\mathrm{mg}$ ) were also prescribed every 8 hour for 5 days. The prosthetic procedure was started 3 months following implant surgery. Definitive impressions were taken at the implantlevel using polyvinyl siloxane (Examix, GC Korea, Seoul, Korea) and transfer impression copings (Shinhung). Customized gold or titanium abutments were made on the master casts in the dental laboratory and metal ceramic gold crowns with the abutment screw access holes were also fabricated. The customized abutments were seated on the implants in the patients' mouths and the abutment screws were tightened to $35 \mathrm{Ncm}$ torque. The definitive screw- and cement-retained crowns with the screw access holes were cemented to the abutments by resin-modified glass ionomer (Fujicem, GC Corp., Tokyo, Japan) and the holes were sealed. These implant-supported restorations were delivered to the patients at 4 months after surgery, having occlusal contacts at the centric positions and no contacts at the eccentric.

A standardized periapical radiograph (Kodak Ektaspeed Plus film, $1512 \times 1134$ pixels, $40 \times 30 \mathrm{~mm}, 256$ grayscale, Eastman Kodak Co., Rochester, NY, USA) was taken using the paralleling technique $(60 \mathrm{kV}, 10 \mathrm{~mA}, 0.250 \mathrm{~s})$ with RINN XCP positioners (Dentsply Sirona, York, PA, USA) at prosthesis delivery (baseline, 4 months after implant placement) and 1 year postloading. This radiographic series for each recruited patient was standardized with the individualized polyvinyl siloxane positioning template for radiogra- phy (Blu-Mousse, Parkell, Edgewood, NY, USA), which had been described in a previous study. ${ }^{22}$ Radiographic images were stored at $300 \mathrm{dpi}$ in tiff format (Infinitt PACS, Infinitt, Seoul, Korea).

An examiner (JCK) conducted repeated measurements of the radiographic parameters using an image analysis program (ImageJ 1.60, NIH, Bethesda, MD, USA). Radiographs were assessed on a 24-inch liquid crystal display monitor (Samsung, Seoul, Korea) under standardized conditions (ISO 12646:2015). Parameters in the radiograph were calibrated with the known width and length of the implants. After training 10 samples, high intraexaminer reliability was achieved. The intraclass correlation coefficients for the radiographic parameters were 0.918 and 0.924 , respectively.

The parameters were calculated as follows (Fig. 3):

DIB: distance from implant shoulder to first bone-toimplant contact (primary outcome)

PA: peri-implant area (secondary outcome)

The average calculated value of the mesial and distal parts was obtained for each implant. The measurement was progressed to the nearest $0.01 \mathrm{~mm}$.

Most outcome variables for data normalization were accepted using the Shapiro-Wilk test $(P>.05)$. Descriptive statistics were displayed using mean and standard deviation. To assess the difference in DIB and PA values between groups and their changes within the groups, parametric independent $t$ test and paired $t$ test were applied, respective-
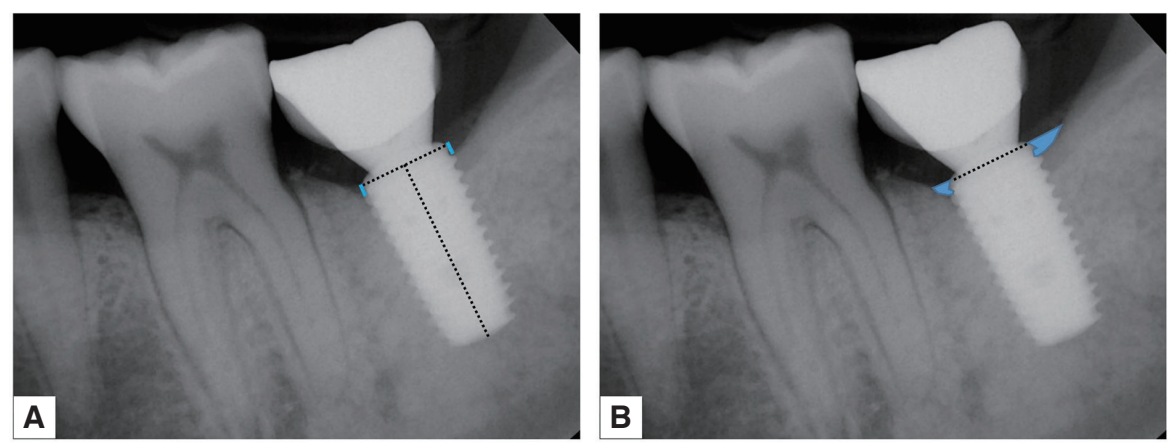

A

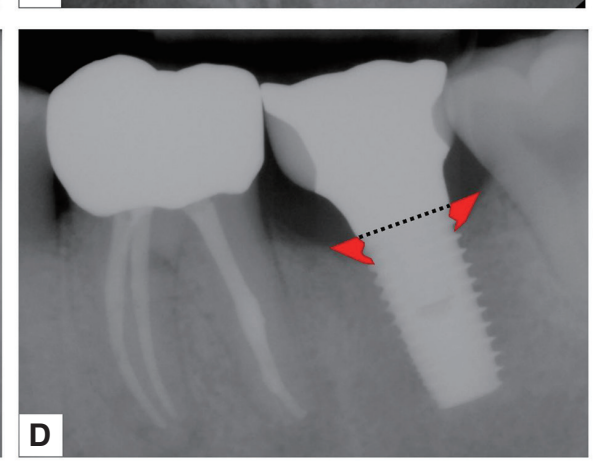

Fig. 3. Schematic of parameters performed in the radiographic analysis. Distance from implant shoulder to first bone-toimplant contact (DIB, blue lines) (A) and peri-implant area (PA, blue areas) (B) of the test group (internal connection structure) were calculated. In the control group, DIB (C, red lines) and PA (D, red areas) were also measured. The black dotted line represents an imaginary line parallel to vertical and horizontal axis of the implants. Digital processing of a radiographic image was performed using ImageJ 1.60 Image Tool software. 
ly. An effect size of Cohen's d was calculated to assess the actual difference in changes of DIB and PA as following formula:

$$
\text { Cohen's d }=\frac{\text { Mean }_{1}-\text { Mean }_{2}}{\sqrt{\frac{\mathrm{n}_{1} \mathrm{SD}_{1}{ }^{2}+\mathrm{n}_{2} \mathrm{SD}_{2}^{2}}{\mathrm{n}_{1}+\mathrm{n}_{2}-2}}}
$$

The interpretation of Cohen's $\mathrm{d}$ is as follows: 0.2 as small, 0.5 as medium, and 0.8 as large effect size. ${ }^{25}$ The statistical software IBM SPSS Statistics Version 22 (IBM Corp., Armonk, NY, USA) was used for the analysis. Statistical significance was set at $P<.05$.

\section{RESULTS}

A total of 24 subjects were recruited and 22 received treatment. One patient in the control group did not receive the allocated intervention due to the participant's decision to change, and one patient in the test group did not return to the treatment program. The antagonistic maxillary second molars were all natural teeth. Eleven implants in 11 patients were assigned to control group (the external connection) and test group (the internal connection). Patient characteristics related to sex, age, smoking, systemic disease, history of periodontitis, reason for extraction, presence of the adjacent 3rd molar, implant length (data not shown), gingival thickness, and bone quality are presented in Table 1. No statistically significant differences were found between the two groups.

Insertion torque was between 25 and $40 \mathrm{Ncm}$ in all implants. No remarkable complications were reported throughout the study. Implants success rate was 100\%, according to the criteria proposed by the International Congress of Oral Implantologists Consensus Conference. ${ }^{3}$ Prosthetic screw loosening was observed once in one subject and two times in one subject (two patients were in the control group). All loose screws were replaced according to the manufacturer's recommendation.

The means of DIB and PA at implant prosthesis delivery (baseline) and at 1 year postloading are shown in Table 2. There were no statistically significant differences between the control and test groups at baseline. The mean changes of DIB from baseline to 1 year were $0.59 \mathrm{~mm}(95 \%$ confidence interval, $-0.05-1.23 \mathrm{~mm})$ and $0.04 \mathrm{~mm}(-0.45-0.47$ $\mathrm{mm}$ ) for external and internal connection structure, respectively. No significance was found in the DIB change between the two groups $(P=0.116)$. However, the effect size of average change between two groups was observed to be medium (Cohen's $d=0.67$ ). Average changes in PA between baseline and 1 year postloading were $0.10 \mathrm{~mm}$ $(-0.21-0.41 \mathrm{~mm})$ and $0.09 \mathrm{~mm}(-0.25-0.43)$ in the control and test groups, respectively, and there was no significant difference between the two groups $(P=0.923)$. The effect size of average change between two group in PA was small (Cohen's $\mathrm{d}=0.02)$.
Table 1. Description of patient distribution recruited in this study

\begin{tabular}{|c|c|c|c|c|}
\hline & \multicolumn{4}{|c|}{ Treatment group } \\
\hline & $\begin{array}{l}\text { Control } \\
(n=11)\end{array}$ & $\begin{array}{c}\text { Test } \\
(n=11)\end{array}$ & $\begin{array}{c}\text { Total } \\
(\mathrm{N}=22)\end{array}$ & Significance \\
\hline \multicolumn{5}{|l|}{ Sex } \\
\hline Male & 9 & 4 & 13 & \multirow{2}{*}{0.080} \\
\hline Female & 2 & 7 & 9 & \\
\hline \multicolumn{5}{|l|}{ Age } \\
\hline Under 45 years & 5 & 4 & 9 & \multirow{2}{*}{1.000} \\
\hline$\geq 45$ years old & 6 & 7 & 13 & \\
\hline \multicolumn{5}{|l|}{ Smoking } \\
\hline Non-smoker & 7 & 10 & 17 & \multirow{3}{*}{0.214} \\
\hline Former smoker & 1 & 1 & 2 & \\
\hline Mild smoker & 3 & 0 & 3 & \\
\hline \multicolumn{5}{|l|}{ Systemic disease } \\
\hline Hypertension & 2 & 2 & 4 & \multirow{3}{*}{1.000} \\
\hline Diabetes mellitus & 1 & 0 & 1 & \\
\hline None & 8 & 9 & 17 & \\
\hline \multicolumn{5}{|l|}{ History of periodontitis } \\
\hline Yes & 5 & 2 & 7 & \multirow{2}{*}{0.361} \\
\hline No & 6 & 9 & 15 & \\
\hline \multicolumn{5}{|l|}{ Reason for extraction } \\
\hline Dental caries & 1 & 2 & 3 & \multirow{4}{*}{0.678} \\
\hline Endodontic failure* & 3 & 2 & 5 & \\
\hline Periodontitis $^{\dagger}$ & 4 & 6 & 9 & \\
\hline Root fracture/crack & 3 & 1 & 4 & \\
\hline \multicolumn{5}{|l|}{ The 3rd molar } \\
\hline Absence & 8 & 11 & 19 & \multirow{2}{*}{0.534} \\
\hline Presence & 3 & 0 & 3 & \\
\hline \multicolumn{5}{|l|}{ Gingival width } \\
\hline$<3 \mathrm{~mm}$ & 4 & 5 & 9 & \multirow{2}{*}{1.000} \\
\hline$\geq 3 \mathrm{~mm}$ & 7 & 6 & 13 & \\
\hline \multicolumn{5}{|l|}{ Bone quality ${ }^{\ddagger}$} \\
\hline 1 & 0 & 0 & 0 & \multirow{4}{*}{0.230} \\
\hline 2 & 6 & 5 & 11 & \\
\hline 3 & 3 & 6 & 9 & \\
\hline 4 & 2 & 0 & 2 & \\
\hline
\end{tabular}

* Endodontic failure is defined here as recurrence of signs or symptoms like periapical lesion and pain after endodontic therapy is finished.

+ Periodontitis is defined here as bone resorption over $70 \%$ of the length of the root with the $3^{\text {rd }}$ degree of tooth mobility.

‡ Bone quality was assessed at implant surgery according to the classification suggested by Lekholm and Zarb (1985). 
Table 2. Comparative mean (95\% confidence interval) and changes in distance from implant shoulder to first bone-toimplant contact (DIB) and peri-implant area (PA) according to different implant connections

\begin{tabular}{|c|c|c|c|c|}
\hline & $\begin{array}{l}\text { External } \\
(\mathrm{n}=11)\end{array}$ & $\begin{array}{l}\text { Internal } \\
(\mathrm{n}=11)\end{array}$ & $P$ value ${ }^{a}$ & Effect size ${ }^{c}$ \\
\hline DIB at baseline & $-0.06(-0.62-0.50)$ & $0.21(-0.45-0.87)$ & .813 & \\
\hline DIB at 1 year loading & $0.53(-0.23-1.29)$ & $0.26(-0.21-0.74)$ & .105 & \\
\hline$\triangle \mathrm{DIB}$ (baseline-1 year postloading) & $0.59(-0.05-1.23)$ & $0.04(-0.45-0.47)$ & .116 & 0.67 \\
\hline$P$ value ${ }^{b}$ & .067 & .837 & & \\
\hline PA at baseline & $0.34(-0.12-0.80)$ & $0.31(-0.13-0.75)$ & .917 & \\
\hline PA at 1 year loading & $0.44(-0.22-1.10)$ & $0.40(-0.02-0.82)$ & .198 & \\
\hline$\triangle \mathrm{PA}$ (baseline-1 year postloading) & $0.10(-0.21-0.41)$ & $0.09(-0.25-0.43)$ & .923 & 0.02 \\
\hline$P$ value ${ }^{b}$ & .495 & .566 & & \\
\hline
\end{tabular}

a $P$ value by independent samples $t$ test.

${ }^{b} P$ value by related samples paired $t$ test.

${ }^{\circ}$ Cohen's d was used as the effect size.

\section{DISCUSSION}

The present clinical study aimed to evaluate the crestal bone response to implant-abutment connection structures. To date, no published randomized controlled trial has evaluated the effect of implant-abutment connection on single implant-supported crowns replacing only the missing second molar. Previous studies that have estimated marginal bone level change have focused on diverse factors, especially with respect to implant location, implant-abutment junction, surgical approach (submerged or non-submerged), implant surface, presence of adjacent tooth, and history of periodontitis. ${ }^{5,15,16}$ However, to preclude aforementioned factors as a variable, the present study had to adhere to strict inclusion criteria (with the only difference being the implant-abutment connection) to have same implant thread design and texture, second molar position, non-submerged protocol, implant diameter $(5 \mathrm{~mm})$, and length falling within the ranges of $8.5-11.5 \mathrm{~mm}$. Fortunately, in our recruited subjects, there were no differences between two groups for extraction option $(P=0.678)$ and history of periodontitis $(P=0.361)$. Therefore, the authors of this study considered the effect of localized and/or generalized periodontitis was minimized enough to compare test and control group.

In the present study, the DIB of the external hex connection tended to increase at 1 year postloading despite of no significance between the baseline and the 1 year postloading due to the small sample size. In this study, we calculated the effect size of Cohen's d. It was interpreted as small, medium, and large corresponding to values of 0.2 , 0.5 , and 0.8 , respectively. ${ }^{25}$ Although the differences could not be confirmed in PA and DIB in terms of $P$-value, the effect size in DIB was observed to be medium. In this point of view, internal connection type might be favorable to peri-implant bone response compared to external hex type. However, we could not observe any differences between control and test group in PA. Initial marginal bone loss is considered to progress linearly to the apical direction and then expand to peri-implant area. As a result, one-dimensional parameter, DIB seems to show a medium effect size (Cohen's $\mathrm{d}=0.67$ ), whereas PA, two-dimensional parameter, exhibits small effect size (Cohen's $d=0.02$ ). However, this result should be accepted carefully and further clinical long-term studies with larger sample size are needed to elucidate the effect of implant-abutment connection type.

Although there are some limits to making direct comparisons, similar studies have shown that internal connection structures exhibited lower values of marginal bone loss with no statistical difference between the connection types. ${ }^{19,26,27}$ Some other studies have shown that internal connection structures exhibited lower levels of marginal bone loss, showing a statistical difference compared with external connection structures although no significant difference was found in implant survival. ${ }^{28-32}$ Those authors concluded that the platform switching concept was largely responsible for marginal bone loss. This concept is based on the research that a bacterial contamination of the implant-abutment interface appears to provoke the inflammatory response. Preventing microbial leakage at the implant-abutment junction has been reported to be a major challenge to minimize inflammatory reactions and to maintain the bone crest level at the junction. ${ }^{33}$ However, there has been a study demonstrating that no difference in bacterial infiltration (Escherichia coli and Streptococcus sanguis) was found between the implantabutment connection structures. ${ }^{34}$

The different biomechanics of implant-abutment connection structures can explain the different tendency in crestal bone responses to implant-supported restorations. The connection type exerts a significant influence on the stress distribution in bone because of the different load transfer mechanisms and differences in the spread of the contact area between the abutment and implant., ${ }^{30,31}$ Stress 
around the peri-implant area has been shown to be higher in the external hex connection compared with that in the internal friction. ${ }^{35}$ More importantly, peri-implant bone strain, which is a key factor to stimulate the bone response, significantly varies depending on the type of implant-abutment connection. ${ }^{13,36}$ The internal friction connection is considered to show more favorable tendency to maintain the bone level by effectively distributing the stress of masticatory or functional load in the mouth, and by efficiently converting the load to the peri-implant bone strain.

\section{CONCLUSION}

Within the limitations of this study, the results of this oneyear randomized controlled trial suggested the possibility of the internal friction connection in more effective maintenance of the marginal bone level, considering the effect size in the vertical bone level change, despite of no significant differences in the bone level between the implant-abutment connection structures. Randomized controlled trials with more samples and long-term follow-up are required to determine the relationship of implant-abutment connection structure and marginal bone response.

\section{ORCID}

Jin-Cheol Kim https://orcid.org/0000-0002-5332-5015

Jungwon Lee bttps://orcid.org/0000-0002-5508-442X

Sungtae Kim https://orcid.org/0000-0001-6361-4104

Ki-Tae Koo https://orcid.org/0000-0002-9809-2630

Hae-Young Kim bttps://orcid.org/0000-0003-2043-2575

In-Sung Luke Yeo bttps://orcid.org/0000-0002-6780-2601

\section{REFERENCES}

1. Lorenz J, Lerner H, Sader RA, Ghanaati S. Investigation of peri-implant tissue conditions and peri-implant tissue stability in implants placed with simultaneous augmentation procedure: a 3-year retrospective follow-up analysis of a newly developed bone level implant system. Int J Implant Dent 2017;3:41.

2. Rotundo R, Pagliaro U, Bendinelli E, Esposito M, Buti J. Long-term outcomes of soft tissue augmentation around dental implants on soft and hard tissue stability: a systematic review. Clin Oral Implants Res 2015;26:123-38.

3. Misch CE, Perel ML, Wang HL, Sammartino G, GalindoMoreno P, Trisi P, Steigmann M, Rebaudi A, Palti A, Pikos MA, Schwartz-Arad D, Choukroun J, Gutierrez-Perez JL, Marenzi G, Valavanis DK. Implant success, survival, and failure: the International Congress of Oral Implantologists (ICOI) Pisa Consensus Conference. Implant Dent 2008;17:515.

4. Albrektsson T, Buser D, Sennerby L. Crestal bone loss and oral implants. Clin Implant Dent Relat Res 2012;14:783-91.

5. Roccuzzo M, De Angelis N, Bonino L, Aglietta M. Ten-year results of a three-arm prospective cohort study on implants in periodontally compromised patients. Part 1: implant loss and radiographic bone loss. Clin Oral Implants Res 2010;21:490-6.
6. Vigolo P, Gracis S, Carboncini F, Mutinelli S; AIOP (Italian Academy of Prosthetic Dentistry) Clinical Research Group. Internal- vs external-connection single implants: A retrospective study in an italian population treated by certified prosthodontists. Int J Oral Maxillofac Implants 2016;31:1385-96.

7. Albrektsson T, Dahlin C, Jemt T, Sennerby L, Turri A, Wennerberg A. Is marginal bone loss around oral implants the result of a provoked foreign body reaction? Clin Implant Dent Relat Res 2014;16:155-65.

8. Baffone GM, Botticelli D, Pantani F, Cardoso LC, Schweikert MT, Lang NP. Influence of various implant platform configurations on peri-implant tissue dimensions: an experimental study in dog. Clin Oral Implants Res 2011;22:438-44.

9. Bateli M, Att W, Strub JR. Implant neck configurations for preservation of marginal bone level: a systematic review. Int J Oral Maxillofac Implants 2011;26:290-303.

10. Hermann JS, Buser D, Schenk RK, Higginbottom FL, Cochran DL. Biologic width around titanium implants. A physiologically formed and stable dimension over time. Clin Oral Implants Res 2000;11:1-11.

11. Broggini N, McManus LM, Hermann JS, Medina R, Schenk RK, Buser D, Cochran DL. Peri-implant inflammation defined by the implant-abutment interface. J Dent Res 2006;85:473-8.

12. van Winkelhoff AJ, Goené RJ, Benschop C, Folmer T. Early colonization of dental implants by putative periodontal pathogens in partially edentulous patients. Clin Oral Implants Res 2000;11:511-20.

13. Nishioka RS, de Vasconcellos LG, de Melo Nishioka GN. Comparative strain gauge analysis of external and internal hexagon, Morse taper, and influence of straight and offset implant configuration. Implant Dent 2011;20:e24-32.

14. Ugurel CS, Steiner M, Isik-Ozkol G, Kutay O, Kern M. Mechanical resistance of screwless morse taper and screw-retained implant-abutment connections. Clin Oral Implants Res 2015;26:137-42.

15. Peñarrocha-Diago MA, Flichy-Fernández AJ, AlonsoGonzález R, Peñarrocha-Oltra D, Balaguer-Martínez J, Peñarrocha-Diago M. Influence of implant neck design and implant-abutment connection type on peri-implant health. Radiological study. Clin Oral Implants Res 2013;24:1192-200.

16. Pozzi A, Agliardi E, Tallarico M, Barlattani A. Clinical and radiological outcomes of two implants with different prosthetic interfaces and neck configurations: randomized, controlled, split-mouth clinical trial. Clin Implant Dent Relat Res 2014; 16:96-106.

17. Shin YK, Han CH, Heo SJ, Kim S, Chun HJ. Radiographic evaluation of marginal bone level around implants with different neck designs after 1 year. Int J Oral Maxillofac Implants 2006;21:789-94.

18. Astrand P, Engquist B, Dahlgren S, Gröndahl K, Engquist E, Feldmann H. Astra Tech and Brånemark system implants: a 5 -year prospective study of marginal bone reactions. Clin Oral Implants Res 2004;15:413-20.

19. Lin MI, Shen YW, Huang HL, Hsu JT, Fuh LJ. A retrospective study of implant-abutment connections on crestal bone level. J Dent Res 2013;92:202S-7S.

20. Misch CE, Suzuki JB, Misch-Dietsh FM, Bidez MW. A posi- 
tive correlation between occlusal trauma and peri-implant bone loss: literature support. Implant Dent 2005;14:108-16.

21. Shinogaya T, Bakke M, Thomsen CE, Vilmann A, Matsumoto M. Bite force and occlusal load in healthy young subjects-a methodological study. Eur J Prosthodont Restor Dent 2000;8:11-5.

22. Koo KT, Lee EJ, Kim JY, Seol YJ, Han JS, Kim TI, Lee YM, $\mathrm{Ku}$ Y, Wikesjö UM, Rhyu IC. The effect of internal versus external abutment connection modes on crestal bone changes around dental implants: a radiographic analysis. J Periodontol 2012;83:1104-9.

23. Canullo L, Rosa JC, Pinto VS, Francischone CE, Götz W. Inward-inclined implant platform for the amplified platformswitching concept: 18-month follow-up report of a prospective randomized matched-pair controlled trial. Int J Oral Maxillofac Implants 2012;27:927-34.

24. Schulz KF, Altman DG, Moher D; CONSORT Group. CONSORT 2010 statement: updated guidelines for reporting parallel group randomised trials. BMJ 2010;340:c332.

25. Cohen J. The $t$ test for means. In: Cohen J, ed. Statistical power analysis for the behavioral sciences. 2nd ed. New York; Lawrence Erlbaum Associates; 1988. p. 20-7.

26. Crespi R, Capparè P, Gherlone E. Radiographic evaluation of marginal bone levels around platform-switched and non-platform-switched implants used in an immediate loading protocol. Int J Oral Maxillofac Implants 2009;24:920-6.

27. Esposito M, Maghaireh H, Pistilli R, Grusovin MG, Lee ST, Trullenque-Eriksson A, Gualini F. Dental implants with internal versus external connections: 5-year post-loading results from a pragmatic multicenter randomised controlled trial. Eur J Oral Implantol 2016;9:129-41.

28. De Angelis N, Nevins ML, Camelo MC, Ono Y, Campailla M, Benedicenti S. Platform switching versus conventional technique: a randomized controlled clinical trial. Int J Periodontics Restorative Dent 2014;34:s75-9.

29. Pozzi A, Tallarico M, Moy PK. Three-year post-loading results of a randomised, controlled, split-mouth trial comparing implants with different prosthetic interfaces and design in partially posterior edentulous mandibles. Eur J Oral Implantol 2014;7:47-61.

30. Caricasulo R, Malchiodi L, Ghensi P, Fantozzi G, Cucchi A. The influence of implant-abutment connection to peri-implant bone loss: A systematic review and meta-analysis. Clin Implant Dent Relat Res 2018;20:653-64.

31. Lemos CAA, Verri FR, Bonfante EA, Santiago Júnior JF, Pellizzer EP. Comparison of external and internal implantabutment connections for implant supported prostheses. A systematic review and meta-analysis. J Dent 2018;70:14-22.

32. Palacios-Garzón N, Mauri-Obradors E, Roselló-LLabrés X, Estrugo-Devesa A, Jané-Salas E, López-López J. Comparison of marginal bone loss between implants with internal and external connections: A systematic review. Int J Oral Maxillofac Implants 2018;33:580-9.

33. Hermann JS, Schoolfield JD, Schenk RK, Buser D, Cochran DL. Influence of the size of the microgap on crestal bone changes around titanium implants. A histometric evaluation of unloaded non-submerged implants in the canine mandible. J Periodontol 2001;72:1372-83.
34. Guerra E, Pereira C, Faria R, Jorge AO, Bottino MA, de Melo RM. The impact of conical and nonconical abutments on bacterial infiltration at the implant-abutment interface. Int J Periodontics Restorative Dent 2016;36:825-31.

35. Khraisat A, Stegaroiu R, Nomura S, Miyakawa O. Fatigue resistance of two implant/abutment joint designs. J Prosthet Dent 2002;88:604-10.

36. Yang TC, Maeda Y. The biomechanical effect of platform switching on external- and internal-connection implants. Int J Oral Maxillofac Implants 2013;28:143-7. 